\title{
The Social Determinants of Routine Immunisation in Ekiti State of Nigeria
}

\author{
Christopher Oluwadare \\ Department of Sociology, University of Ado Ekiti, P.M.B.5363, Ado Ekiti, Nigeria \\ E-mail: ctoluwadare@yahoo.co.uk
}

KEYWORDS Health. Poverty. Factors. Infant. Child Mortality

\begin{abstract}
The greatest challenge to child health in sub Saharan Africa is poor immunization service for major child illnesses. The World Health Organisation's (WHO) review of the health systems of the World, looking at various health indicators including child mortality, in the year 2003 placed Nigeria in $187^{\text {th }}$ position among 191 countries, and little has been achieved since then. This paper is an overview of routine immunization in Ekiti State of Nigeria. The State serves as a case for understanding the prospects and challenges of child health care in South Nigeria. The study used qualitative data derived from focus group discussions and key informants and secondary data of state and national surveys. The findings identify factors that account for the relative poor immunization coverage. The salient issues include ignorance and social cost of access to the service. Also the quality of the immunization service: availability to the remote areas, health personnel commitment, and consistent availability account for low coverage. It is concluded and recommended that there is a need for improvement in the supply side of immunization service especially taken the service to the physically and socially marginalized areas and also extend the campaigns for immunizations beyond the current emphasis on Polio vaccination to incorporate other antigens.
\end{abstract}

\section{INTRODUCTION}

Nigeria has a very high under-five and infant mortality rates of 201 and 100 respectively. This is one of the highest in the world. Most of the childhood deaths are due to malaria, diarrhoea, pneumonia, measles and malnutrition. Also due to the significant population size of the country, childhood mortality accounts for a significant percentage of deaths nationally (Nigeria Demographic and Health Survey (NDHS), 2003). This situation is directly related to the worsening condition of health care services which include the Maternal and Child Health $(\mathrm{MCH})$ programmes. One global health intervention to improve child health is the Extended Programme of Immunisation (EPI). Generally the whole Nigerian health system is facing great challenges. It is noted that more than half of child deliveries take place outside of the modern health facility and the use of child preventive health service is low. (Oral rehydration therapy, treated bed nets, breastfeeding and immunisation) (Dada 2005).

The Extended Programme on immunisation, introduced in 1979 with the aim of providing routine immunisation to children less than the age of two years, recorded initial but intermittent successes. The optimum level was recorded by early 1990s with the country achieving universal childhood immunisation of 81.5 percent coverage. But since that period of success, Nigeria has witnessed gradual but consistent reduction in immunisation coverage. By 1996, the national coverage data showed less than $30 \%$ coverage for the entire antigens, by the 1999 NDHS, this has reduced to $16.8 \%$ for all antigens and by 2003, it was $12.9 \%$ (Babalola and Olabisi 2004). This figure is consistent with the 2003 National Immunisation coverage survey figure. This current national figure is among the lowest in the world and explains the poor health status of children in the country; the worst in the west African sub region, only better than Sierra Leone. For instance the Polio epidemic in Nigeria is the worst in the African region also constituting a threat to other nations (Green 2004).

This epidemic is a reflection of the growing concern for the worsening human development index of the country, the millennium development goals of reducing child mortality and improving survival by 2015 is frustrated by the poor immunisation service. There is therefore the urgent need to address specifically and concretely the problem facing immunisation activities in the country. Most data available is not aggregated to ethnic, state and social conditions of the population and health interventions have also been generic. These produce little return for the 
socio political and economic investments to improve health of the mothers and children especially immunisation.

\section{RESEARCH PROCESS}

This study was conducted in 2005 with the sole intention to explain the intractable plummeting trend of immunisation in Nigeria and in Ekiti State as a case study. Given the already existing statistics of immunisation for the state though not disaggregated into social variables, the data provided the background information across the state. After review of the relevant literature, six local government areas (LGAs) were selected to represent areas of low and high coverage and a mix of population groups, such as urban Yoruba and ethnic minority rural settlers. Qualitative research was carried out in the six LGAs, which were: Efon, Moba, Ikole, Ekiti South West, Gbonyin and Ekiti East. Some additional fieldwork was also conducted in the State capital. In these areas the following research methods were used to collect data:

- focus group interviews with mothers and government health workers;

- key informant interviews with community leaders and health workers;

- Semi-structured interviews with mothers, fathers, elderly people and adolescents. A range of qualitative research methods were applied during two day visits to each of the study sites.

Focus group interviews were conducted with parents and health staff, with the assistance of local leaders. In addition, when the opportunity arose, informal, natural group interviews were conducted. For example, in two small communities where we met the people both male and female under the shed with their respective leaders, we took time to hold meeting with them on their issues around immunisation. In another settlement among migrant labourers, the women refused to talk separately from their husbands, we therefore agreed to talk to both sexes together. These afforded a novel opportunity to confirm on the spot a whole range of topics with gender, cultural and economic influences.

A basic discussion guide was used for both focus and natural group interviews. Informal, semi-structured interviews were held with the following:

1. Mothers of fully, partially and non-immunised children;
2. Fathers of fully, partially and non-immunised children;

3. Grandmothers with fostered children

4. Young people, male and female

5. And providers of immunisation in clinics and where available in mission hospitals and traditional birth attendants.

During the interviews information about their own and any children's immunisation history was elicited. The interviews also included questions that probed views and knowledge about immunisation, experience of local service provision and reasons for completion/non-completion of vaccination programmes for themselves or family members.

During the in-depth interviews, interesting stories (both good and bad in terms of health outcome) recounted by participants concerning local immunisation histories were focused on as case studies. The aim was to look for case studies that illustrated barriers to immunisation and led to unhappy outcomes, as well as positive stories where full immunisation was achieved despite obstacles.

Key informant interviews were carried out with individuals who might particularly influence people concerning the up-take of immunisation. At the community level they included: Religious leaders of both Muslim and Christian faith; Political leaders especially at the local level; Women leaders; Patent medicine hawker/ provider; Faith- based maternity centre staff (Anglican, Christ Apostolic Church and Catholic faithfuls); Director, Primary Health Care, State Ministry of Health; The WHO representative in the State; traditional leaders. This paper is a part report of a descriptive study of the barriers to the uptake of routine immunisation in Ekiti State of Nigeria (Beckerleg and Oluwadare 2005)

\section{HEALTH SITUATION IN EKITISTATE}

Ekiti state is in the southwest geo-political zone of Nigeria with a population of about two and half million people and annual population growth rate of $3 \%$. There are 16 local government areas, mostly of less than two hours drivedistance to the state capital (Ado-Ekiti). The basic occupation of the people is agriculture mainly cocoa, coffee, rice, cassava, maize and vegetable cultivation. Roads linking the state capital to local government headquarters are relatively good but those to the remote communities are mostly in disrepair (Ekiti-State 2004). 
There are about 174 functioning primary health care centres across the state, 4 state specialist hospitals, 17 state general hospitals and one federal medical centre. The latter is the highest referral point in the State. Virtually all the state health structures (buildings and also personnel) were from the old Ondo State with continuous rehabilitation and improvement in facilities (Dare 2005). There are other private health providers of varying qualities across the State. Notwithstanding, more than $60 \%$ of all deliveries take place outside of the public health system; the infant mortality rate is about $7 \%$, due to mostly malaria, diarrhoea, pneumonia, and malnutrition. Also only $34 \%$ of all immunisable children receive full doses of Diphtheria, Pertusis and Tetanus vaccines (Ankrah and Nwaigwe 2005). As at the time of study the GAVI's (Global Assistance for Vaccines and Immunisation) fund was being processed as technical support for the State and all local government cold chain stores to improve the immunisation provision. Equally the Department for International Development (DFID) was working with the State Ministry of health to also provide systemic review in preparation to support improvement in immunisation delivery in the State. The impact of these will not be immediate in terms of numeric improvement in immunization utilization
Data about immunisation in the state shows that though coverage is higher than the national figure, it is still far from the expected in line of the millennium development goals. Table 1 shows the immunisation coverage in the state by local government areas. It also attempts to show the differentiation along urban, semi urban and rural areas. The data indicate that urban communities have highest coverage level for all antigens. The urban areas equally have the best health facilities (specialist hospitals) except Efon-Alaaye with only a general hospital. They are the most cosmopolitan and socially accessible to health related communications.

The basic difference between semi urban and rural areas is the level of socio-cultural homogeneity and pattern of occupational diversity. While all the local government areas have at least a general hospital each, the typically rural areas are more to be wholly into peasant farming, and at best have few primary and secondary teachers. The rural areas are also to have at least a primary health centre in the communities. The recent community state development survey shows that more rural local government areas will also have more small communities with less than five thousand populations (Ekiti State 2004).

The figure reflects the poor immunisation

Table 1: Percentage of infants receiving selected immunisations by local government areas for 2005 in Ekiti State, Nigeria.

\begin{tabular}{|c|c|c|c|c|c|}
\hline $\begin{array}{l}\text { Local government } \\
\text { areas }\end{array}$ & $\begin{array}{c}2005 \text { Population } \\
\text { (In ,000) }\end{array}$ & $B C G$ & $O P V$ & $D P T$ & Measles \\
\hline Urban & 519,413 & 59 & 52 & 43 & 41 \\
\hline Ado & 254,417 & 59 & 49 & 37 & 44 \\
\hline Efon & 117,387 & 61 & 70 & 44 & 58 \\
\hline Ikere & 87,294 & 76 & 62 & 57 & 43 \\
\hline Ijero & 139,498 & 67 & 55 & 58 & 43 \\
\hline Ikole & 175,234 & 30 & 22 & 20 & 18 \\
\hline Semi urban & 932,739 & 55 & 46 & 40 & 38 \\
\hline Moba & 187,859 & 69 & 47 & 47 & 62 \\
\hline Oye & 168,576 & 79 & 71 & 54 & 50 \\
\hline Irepodun/ifelodun & 161,286 & 50 & 33 & 26 & 24 \\
\hline Gbonyin & 99,142 & 46 & 32 & 32 & 22 \\
\hline Ekiti east & 95,156 & 65 & 57 & 55 & 51 \\
\hline Ekiti west & 203,521 & 20 & 33 & 27 & 19 \\
\hline Ekiti South West & 205,058 & 20 & 16 & 16 & 16 \\
\hline Rural & 379,698 & 30 & 29 & 24 & 23 \\
\hline Ise orun & 112,633 & 39 & 45 & 29 & 34 \\
\hline Emure & 92,763 & 19 & 15 & 14 & 19 \\
\hline Ilejemeje & 30,096 & 31 & 32 & 34 & 19 \\
\hline Ido osi & 144,206 & 30 & 22 & 20 & 19 \\
\hline Ekiti State & $2,274,126$ & 48 & 43 & 37 & 36 \\
\hline
\end{tabular}

Source: Ekiti State Ministry of Health, Health Management Information System office, 2006 
delivery and utilization across the state. The very rural areas are least enviable. This is contrary to the expectation that primary health care should uptake the immunisation delivery. The explanation for this fact is both social and institutional. This relative urban areas are more favourable to immunisation than the rural areas especially in the provision while rural areas have unmet need for the service.

\section{PATTERN OF ROUTINE IMMUNISATION}

From the study, it was shown that most urban health centres conduct immunisation twice in a month on either Wednesday or Thursday. In the rural areas, depending on the availability of the vaccines and transportation, it takes place also twice in a month. But the provision of any antigen is contingent on the availability and supplies from the Central Cold Store. Relatively small public clinics are served by either the nearest referral centre or taken as outpost during the stipulated immunisation days or market days. Theoretically following the nation-wide immunisation guideline, some settlements are designated as "hard-to-reach" due to bad topography, impassable river, long distance to service point, and political unrest. These areas if found should be served by a mobile immunisation team. But, in all identified "hard-to-reach" areas in the State, routine immunisation by itinerant health workers is not consistently in operation.

These areas are reachable by either vehicle, motorcycle or by trekking some of the distance. The health workers either do not have financial support to fuel the vehicle or complain of insufficient personnel. It is therefore established that when most of the mothers in the 'hard to reach' areas could not visit the health centre on immunisation days; their children miss the opportunity of being immunized. For instance, a community of less than a thousand people and less than four kilometres to a comprehensive health centre in Gbonyin local government was tagged hard to reach and was not visited by the immunisation team except during polio rounds. The significant issue is lack of motivation for the health staff to do the itinerant immunisation to designated places.

These are a number of entry-points to the government health system whose most mothers and children access routine immunisation:

1. Mothers who attend ante-natal clinic in public heath facility are likely to deliver there and access immunisation at the clinic or hospital.

2. Mothers are referred from traditional birth attendants or private faith based delivery homes to the nearest public clinic for immunisation.

3. Mothers take their babies to government facilities seeking curative services and are offered immunisation.

The first entry-point is the strongest and accounts for the continuous patronage of routine immunisation. Except in a few local government areas, like Ekiti West, and Moba, there is a critical rift between faith-based homes and public health workers, which hinder the desired complementary relationship. From table 1, LGAs with more prevalence of "hard to reach" areas have relatively low immunisation coverage. Hard to reach areas socially include also non-native farm or migrant settlements, mostly of more than three kilometres from the nearest health centre and also access is hindered by bad roads. Examples are Ekiti West, Ikole and Gbonyin LGAs. The only exception is Efon Alaaye where the hard to reach areas are due to very bad topography and the settlers are mostly town dwellers, visit the town by weekends and non natives during market days.

\section{Knowledge of Routine Immunisation}

The knowledge of routine immunisation is good. Most mothers interviewed, whether individually or in groups, know the purpose of immunisation and could name some of the diseases which children could be vaccinated against.

However one common misconception is that immunisation protects against all diseases. This belief is prevalent in remote settlements where polio vaccinations always reach. The people interviewed took polio as general vaccination for all the other childhood diseases. The tendency is for this category of people, including men, not to bother with other immunisation antigens and also take immunisation as ineffective when child illness arises. Some communities of Muslim settlers from north central Nigeria were encountered who had little or even no knowledge of immunisation. Most of the typically remote rural settlements have not immunized their children against any of the childhood diseases, but relied on the annual polio vaccination. It was worrisome in all of these settlements that between 2-3 children were identified in any camp with untreated chronic measles and others with diarrhoea 
and malaria. The team of researchers took time after the community discussion to educate the affected mothers on the need to take their children for immunisation and other health care services.

The general complaints of the settlers are bad road access to the public clinic located in the local government headquarter about ten kilometres away. In most of these farm camps, commercial vehicle moves once in a day. Also it was alleged that the health workers demand money for the services. The latter case was a product of misconception among the poor settlers. It is mandatory for a public service user to produce evidence of payment of annual development levy fund of two hundred naira per adult, equivalent of three dollars. Most of the poor cannot afford this and so desert public facilities, especially children's education and health services.

The main source of information regarding immunisation is the health clinic in all the local government areas. Health authorities work through town criers, churches and mosques to get information to the people especially on polio vaccination. Polio immunisation programme tends to overwhelm information and communication about other antigens.

\section{Influence of Religion on Acceptability of Immunisation}

In Nigeria, the greatest challenge to the acceptance of immunisation is religiously entrenched especially among the Northern Nigeria Muslims. At the national level, 2003 Nigeria Development and Health Survey does not have religion as a factor for analysis. But generally the Muslim North has the least immunisation coverage, the least being $6 \%$ (north East) to the highest as $44.6 \%$ (south east).

Ekiti State is one of the six states in Southwest Nigeria. The state is acknowledged to have the highest educational attainment in the nation; hence the state is described as 'the Fountain of Knowledge'. The North East and West of Ekiti, with more Islamic influence have low immunisation coverage and also poor educational attainment. In Babalola and Adewuyi (2005), Christians have $24.2 \%$ immunisation coverage compared to $8.8 \%$ for Muslims. In Ekiti state through discussions and in depth interviews with Muslim clerics and women in both rural and urban areas show support for immunisation and repudiation of the northern Nigerian myths around immunisation, Yet, Muslims in typically isolated settlements of sedentary farmers, cattle nomads, do not show significant immunisation patronage beyond Polio vaccines. The isolated settlements of farmers mostly of southwest origin show better patronage of immunisation. The latter is more likely to visit the nearest primary health centre on market days or other day to get their children immunized. The most significant Christian voice concerning immunisation is among the sect of the first charismatic movement in the south west Nigeria; the Christ Apostolic Church. The adherents hold the doctrine of non use of drugs to treat ailment except the use of prayers and fasting. This doctrine is given way rapidly and the mothers are cooperative to immunisation service. This is due to the persistent advocacy and sensitisation led by the community leaders.

The greater explanatory factor is not religion itself, but religiously fuelled social tendencies of poor education, low economic status and isolated livelihood, which predict low uptake of immunisation. Waisbord and Larson $\{2005\}$ identified four key challenges to the improvement in immunisation acceptance. These include; poor knowledge of the value of vaccine, poor physical access to the immunisation service, lack of trust of the safety of vaccine, and non-availability (poor supply) of the vaccines. In this context, the trust factor is most relevant that is poor knowledge of the whole information about immunisation fuelled by relative social and physical exclusion of migrant farmers and settlements. The exposition in Furula and Salway $\{2006\}$ again supports the positive impact of improved maternal education and income to health care use including immunisation (also in Caldwell 1994 and Oluwadare 1994)

\section{Cost of Immunisation to Service Users}

There is variation in the cost of immunisation to consumers. According to mothers in group discussions and in-depth interviews, the cost of routine immunisation in the health facilities is twenty naira either per unit or per antigen. In a few facilities It is free, or cost fifty naira. In most group discussions, argument ensued on the actual cost but it generally ranges between twenty and fifty naira. Some mothers defended 
the health workers by denying payment, or justifying the payment as been used to provide disposable syringes. The consensus is that payment is made for all antigens. Discussion with the health workers confirmed the payment. They explained that the payment though small is to cover the cost of syringes, while few of the health workers denied ever collecting money for immunisation. The fact is that National Guideline prescribes free immunisations, which cover the free provision of dispensable syringes. In Orubuloye (1991, 1998), most southern Nigerian women contribute mostly to the cost of treatment of children's ill- health. But when treatment is a bit high, the husband is likely to contribute significantly. By extension also; when the cost of treatment is relatively high, the input of husbands in decision-making and payment is needed. This has been argued in Jegede's (1998) report of immunisation study in southwest Nigeria. Most women tend, to be more involved in decision making when their levels of income or education are appreciable.

Among the rural mothers, the cost of health care, including immunisation, usually goes beyond the cost of syringes. It includes the cost of physical access to the source of the service. In this study, Yoruba women in both rural and urban areas were in charge of decision-making and payment for immunisation services. Among Muslim Ebira, Fulani and Gaa (Kwara State), the situation was different. Men and women in group discussion agreed that a woman should inform/ ask permission of her husband before taking children for immunisation. However it was stressed that fathers are very unlike to object to children being immunized. Mothers in isolated settlements, far from the health facility need more money for transportation and will spend more hours outside of the home than those in the towns; therefore they need both financial and social support to access immunisation site from husbands. Table 1 shows that areas with more isolated communities and far from the nearest health centres and dependent on trekking for transportation have relatively low immunisation coverage. The examples are in Ikole, Ekiti West and Ekiti South West areas.

\section{Community Involvement in the Promotion of Routine Immunisation}

In most communities, the involvement of the people is not limited to routine Immunisation but the whole health system, at the very rural areas health facilities were either built or are maintained as part of community development programmes. The most obvious input of the community effort to support immunisation is more in the polio campaign, which is a house-to-house activity. Most of the people interviewed therefore confused the polio campaign with the facility based routine immunisation. From interviews with Community Health Committee members, some of the key informants, especially men, could not make a clear explanation of the immunisation procedure, but instead focused on polio.

\section{CONCLUSION AND RECOMMENDATIONS}

This study has revealed that most parents have a good knowledge of the benefits of routine immunisation, but that accessing the service is not always easy. There are no specific cultural, social or religious barriers to routine immunisation. Neither, at the community level, is there evidence of rumours or scare stories that are deterring parents from taking their children for routine immunisation. But people living in remote and physically and ethnically isolated settlements tend to be marginalized within Ekiti. There is no evidence that such communities suffer overt discrimination from health workers when they access health services, but their minority status coupled with their physical isolation clearly put them at a disadvantage. For example, some communities visited did not speak Yoruba, or did not speak it well. Where there are significant numbers of marginalized non-Yoruba settlers should be the focus of a focussed campaign to rural areas.

Barriers to the uptake of routine immunisation stem primarily from the supply-side. At best, routine immunisation is available weekly. However, a monthly service, that may or may not be reliable, is more common. Health staff complains of lack of freezers, generators and vehicles with running grants with which to operate an effective cold chain. The recent review of the level of service provision in terms of personnel and infrastructures issues (Ankah and Nwagwe 2005) highlighted the successes and challenges of delivering routine immunisation in Ekiti State. The more proactive intervention is to accelerate the provision of needed infrastructural support to routine immunisation and encourage the health 
workers to follow protocol by making available fund for overhead costs like transport and syringes.

The biggest factor affecting uptake of immunisation appears to be whether a family lives in a rural area or a town. This rural/urban factor is linked directly to the availability of services. Although ideally, there are health facilities in many rural areas, staffed by qualified personnel, in reality this is not the case. Most rural areas are without a sitting qualified nurse or senior health officer and most are left to the least unskilled assistants. Access to central supply of vaccines is hindered by poor commitment to the service, non release of financial support and bad road networks. Other rural people must travel considerable distances to urban health facilities to access routine immunisation offered on specific days. Although many health workers claimed to carry out 'outreach' for routine immunisation to rural areas, there was no evidence of it. Therefore the whole issue of health should be taken up as part of human development. Rural road networks should be rehabilitated.

\section{ACKNOWLEDGEMENTS}

The study was supported wholly by Partnership for Transforming Health Systems in Nigeria (PATHS), a Department for International Development (British Council) funded project. The authors are grateful to Ms. Caroline Vanderick; the Team leader for her assistance and Dr. Kolawole Maxwell; the programme officer for technical input. The research was carried out by Susan Beckerleg and Christopher Oluwadare. I thank Susan Beckerleg for her comments on this paper.

\section{REFERENCES}

Ankrah V, Nwaigwe F 2005. Immunisation System Review and Training Needs Assessment in Ekiti State. February. Ado Ekiti: State Ministry of Health.

Babalola Stella, Aina Olabisi 2004. Community and Systematic Factors Affecting the Uptake of Immunisation in Nigeria: A Quantitative Study in Five States. Abuja: Department of International Development (DFID). Nigeria

Babalola Stella and Alfred Adewuyi 2005. Factors Influencing Immunisation Uptake in Nigeria: A Theory Based Research in Six States. Abuja: Department of International Development (DFID).

Becker MH, Mainman IA 1975. Social behavioural determinants of compliance with health and medical care recommendation. Medical Care, 13 (10): 1-24.
Beckerleg Susan and Christopher Oluwadare 2005. Rapid Demand- Side Assessment of Barriers to Uptake of Immunisation. Abuja: Partnership for Transforming Health System (PATHS).

Caldwell John C 1994. How is greater maternal education translated into lower child mortality? Health Transition Review, 4(2): 224-229

Dada Ayoola 2005. Access and Use of Maternal Health Facility in Selected Communities in Ido Osi Local Government Area, Ekiti State, Nigeria. M.Sc dissertation (Unpublished), Ibadan: University of Ibadan.

Dare Lola 2005. Health Component: Ekiti State Economic Empowerment and Development Strategy (E-SEEDS): An Overview. Ibadan: CHESTRAD International.

Ekiti State 2004. Report of the Community Development Statistics Survey 2004. The State Department of Research and Statistics, Ado-Ekiti: Ministry of Finance and Budget. August

Furuta Marie, Salway Sarah 2006. Women's Position within the Household as a Determinant of Maternal Health Care Use in Nepal. International Family Planning Perspectives. 32(1): 17-27

Federal Office of Statistics 2002. Core Welfare Indicators Survey. Ekiti State. Abuja: Federal Office of Statistics

Green Cathy 2004. Demand for Immunisation and IMCI in Nigeria:An issues paper. Background paper prepared for the PATHS Immunisation and IMCI roundtable. Final Version, Abuja: Partnership for Transforming Health Systems (PATHS).

Goshman DS 1972. The organising role of motivation in health beliefs and intention. Journal of Health and Social Behaviours, 13: 285

Jegede SA 1998. African Culture and Health. Ibadan: Stirling Horden Publishers

National Population Commission 2002. 1999 Nigeria Demographic and Health Survey. Abuja: National Population Commission and ORC. Macro.

National Population Commission (NPC) Nigeria and ORC Macro 2004. Nigeria Demographic and Health Survey 2003; Calverton, Maryland: National Population Commission and ORC Macro.

National Population Commission (Nigeria) and ORC Macro 2004. Nigeria DHS EdData Survey 2004: Education Data For Decision Making. Calverton, Maryland, USA: National Population Commission and ORC Macro.

Oluwadare CT 2001. Socio-cultural Factors Influencing Breast-Feeding in Ondo State, Nigeria. Ph.D Thesis (Unpublished), Ibadan: University of Ibadan, Nigeria Orubuloye IO, Caldwell P, Caldwell JC, Bledseo CH 1991. The impact of family and budget structure on health treatment in Nigeria. Health Transition Review, 1(2): $189-210$

Orubuloye IO 1998. Health treatment in Nigeria: Cultural, Social and Behavioural Determinants. Canberra: Health Transition Centre, The Australian National University.

Orubuloye IO 2002. Health, Illness and Disease. Ado Ekiti: Centre for Population and Health Research. 
Population Reference Bureau 2005. 2005 World Population Data Sheet. Washington, DC: Population Reference Bureau.

Rosenstock IM 1966. Why People Use Health Services. Milibank Memorial Quarterly. 44: 94-124

Waisbord S, Larson HJ 2005. Why Invest in Commu- nication for Immunisation. Evidence and Lessons Learned. New York: A joint publication of health communication Partnership based at Johns Hopkins Bloomberg School of Public Health / Centre for Communication Programs (Baltimore) and the United Nations Children's Fund. June. 